\title{
Preparation and Characterization of a Novel Terbium Complex Coordinated with 10-Undecenoic Acid for UV-Cured Coatings
}

\author{
Chenjie Jiao, Rong Zhong $\mathbb{D}^{D}$, Yanfang Zhou, and Hongfei Zhang \\ School of Environmental and Chemical Engineering, Nanchang Hangkong University, Nanchang 330063, China \\ Correspondence should be addressed to Rong Zhong; nuazr@163.com
}

Received 12 July 2019; Revised 13 December 2019; Accepted 14 January 2020; Published 3 February 2020

Academic Editor: Yulin Deng

Copyright () 2020 Chenjie Jiao et al. This is an open access article distributed under the Creative Commons Attribution License, which permits unrestricted use, distribution, and reproduction in any medium, provided the original work is properly cited.

\begin{abstract}
A UV-cured composite containing a rare earth complex was prepared for this study. First, the photoluminescent terbium complex was synthesized with a long-chain unsaturated fatty acid (10-Undecenoic acid) by a solution precipitation method, resulting in the $10-\mathrm{UA}-\mathrm{Tb}$ (III) complex. Its structure was proven by FTIR, elemental analysis, XRD, and TGA. The results indicated that the organic acid ligand successfully coordinated with the $\mathrm{Tb}^{3+}$ ion and that the complex had a chelate bidentate structure. The emission spectrum of the 10-UA-Tb(III) complex indicated that the complex can emit a bright green light with the unique luminescence of the $\mathrm{Tb}^{3+}$ ion. Furthermore, the luminescence properties of complexes with different ratios of $\mathrm{Tb}^{3+}$ and ligand were studied, and the ratio of $\mathrm{Tb}^{3+}$ and the ligand had an obvious impact on the luminescence intensity of the 10-UA-Tb(III) complex. Subsequently, the prepared rare earth complex was doped into a UV-cured coating in different proportions to obtain a UV-cured composite. The morphology of the rare earth UV-cured composite was observed by SEM. The images showed that the rare earth complex was dispersed uniformly in the polymer matrix. Moreover, the composites could emit fluorescence. Additionally, it has good thermal stability and compatibility with the resin. Therefore, these composites should have potential applications in UV curable materials, such as luminescence coatings.
\end{abstract}

\section{Introduction}

Lanthanide elements have excellent features that are unique to $4 \mathrm{f}$ electronic structures, such as abundant energy level transitions, large atomic magnetic moments, and strong spin coupling [1]. Moreover, when rare earth elements combine with other elements to form rare earth complexes, the crystal structure of the rare earth complexes will be diversified due to the coordination number being varied from three to twelve [2]. Therefore, rare earth elements and complexes are endowed with unique electrical, optical, magnetic, and thermal properties that have attracted widespread attention $[3,4]$. In particular, the luminescence properties of rare earth ions have many applications, such as luminescent probes [5] and sensitizers for electroluminescent devices [6]. However, due to the weak light emitted from lanthanide ions themselves, they need suitable ligands to absorb ultraviolet light and then transmit the energy to the lanthanide ions to emit luminescence. The ability of organic ligands to sensitize rare earth ions is called the "antenna effect" [7]. Hence, organic ligands need to meet the following requirements: good ultraviolet absorbance, highly efficient energy transfer, acceptable energy in the launching state, and a moderate lifetime [8]. Rare earth organic ligands fall into three major categories: $\beta$-diketones [9], organic carboxylic acids [10], and supramolecular macrocycles [11]. Among them, the coordination ability between rare earth ions and organic carboxylic acids is strong because rare earth ions are hard acids, and oxygen atoms in carboxylic acids are hard bases whose coordination is in accordance with the affinity principle of acids and bases [12]. Furthermore, the coordination between carboxylate oxygen ions and lanthanide ions can be of various forms, such as a chelated bidentate, bridged bidentate, and monodentate; as a result, rare earth carboxylic acid complexes have numerous special structures, such as lamellar, catenulate, and reticular, which are relatively stable [13].

$\mathrm{UV}$-curing technology is a green technology that is considered a " $5 \mathrm{E}$ " technology due to many advantages, including high efficiency, wide adaptability, low cost, low energy cost, and environmental friendliness [14]. Moreover, UV-curing 


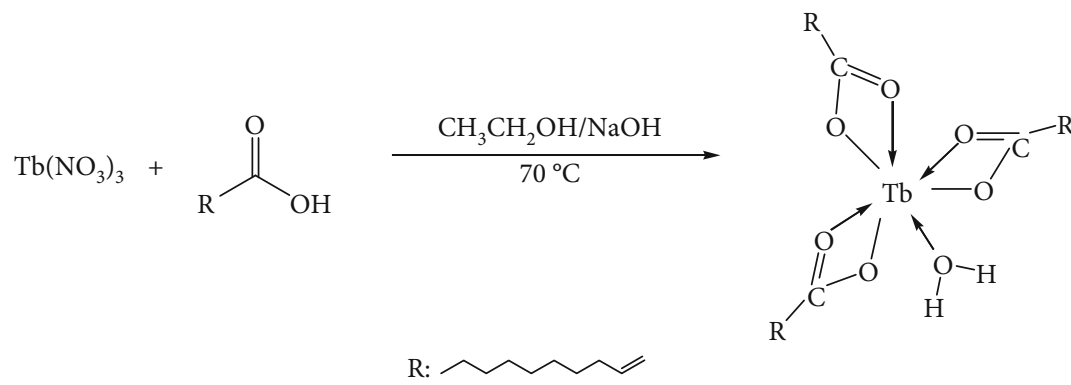

Figure 1: The synthetic route of the 10-UA-Tb(III) complex.

technology possesses other advantages, such as having simple operating conditions, requiring low equipment investment and being a relatively mature technology [15]. Thus, UVcuring technology has a wide range of applications as a coating [16] and adhesive [17] and in 3D printing [18]. In recent years, organic-inorganic hybrid materials have also received extensive attention because the utilization of nanosized inorganic particles is capable of improving the properties of polymers $[19,20]$. It has been reported that nanoparticulate $\mathrm{SiO}_{2}$ [21], $\mathrm{TiO}_{2}$ [22], $\mathrm{ZnO}$ [23], and polyhedral oligomeric silsesquioxanes (POSS) $[24,25]$ have been introduced into UV-cured systems and have shown improved properties. However, studies on the introduction of rare earth complexes into UV-cured systems have rarely been reported [26, 27]. In this work, the rare earth complexes were synthesized by solution precipitation, after which the rare earth complexes were doped into UV-cured systems form rare earth polymer composites. In order to obtain the desirable luminescent properties of UV curable materials, we dope fluorescent terbium complex into the UV curable system. And the composites will be new potential applications in the UV-curing fields.

Most rare earth complexes select aromatic cyclic carboxylic acids as ligands because they contain conjugate double bonds and rigid plane structures that have good absorption in the ultraviolet region [28-31]. Nevertheless, this study selected unsaturated fatty acids called 10Undecenoic acids to coordinate with terbium ions that can emit a bright pure green light. The double bond and long chain of 10-Undecenoic acid could improve the compatibility of the rare earth complexes in the polymer matrix. The structural characterization of rare earth complexes was investigated by FTIR, XRD, and elemental analysis. The morphology of rare earth complexes and rare earth UVcured composite was observed by SEM. Their luminescence properties and thermal stability were tested by a fluorescence spectrometer and TGA, respectively. The mechanical properties of the composite films were tested, including pencil hardness, adhesion, and flexibility.

\section{Experimental Section}

2.1. Materials and Instruments. $\mathrm{Tb}_{4} \mathrm{O}_{7}(99.99 \%)$ was purchased from Ganzhou Zhanhai Industrial and Trading Co., Ltd.; 10-Undecenoic acid (10-UA, AR) was obtained from Aladdin Chemistry Co., Ltd. (Shanghai, China); B-369 urethane acrylate, Irgacure 1173 photoinitiator, and reactive diluent TMPTA were all industry grade and were bought from Guangdong Boxing New Material Technology Co., Ltd. Other chemicals were supplied by Xilong Scientific Co., Ltd. and used without further purification.

The instruments used in this work included a Magna 380 infrared spectrometer (Nicolet Company, USA), F-7000 fluorescence spectrometer (Hitachi Co., Ltd., Japan), TG-209 thermogravimetric analyzer (Netzsch Company, Germany), Nova Nano SEM 450 field emission scanning electron microscope (FEI Company, USA), Flash EA1112 elemental analyzer (Thermo Company, USA), D8 ADVANCE X-ray diffractometer (Bruker Company, Germany), ST $1 \mathrm{KW}$ 230MM 220V UV-curing machine (Dongguan Ergu Photoelectric Technology Co., Ltd., China), and QHQ-A Portable Pencil Scratch Tester and QFH film masker (Tianjin Yonglida Material Testing Machine Co., Ltd.).

2.2. Synthesis of 10-UA-Tb(III) Complex. The synthetic route of the 10-UA- $\mathrm{Tb}$ (III) complex is shown in Figure $1 . \mathrm{Tb}_{4} \mathrm{O}_{7}$ $(0.5 \mathrm{mmol}, 0.374 \mathrm{~g})$ was dissolved in a mixed solution containing excess concentrated nitric acid and 10\% hydrogen peroxide, and the mixture was heated to make the solution transparent. Then, the solution heating continued to remove excess nitric acid until it appeared as a white solid, resulting in $\mathrm{Tb}\left(\mathrm{NO}_{3}\right)_{3} \cdot 6 \mathrm{H}_{2} \mathrm{O}$. After cooling, the $\mathrm{Tb}\left(\mathrm{NO}_{3}\right)_{3} \cdot 6 \mathrm{H}_{2} \mathrm{O}$ was dissolved in $20 \mathrm{~mL}$ anhydrous ethanol. The 10-Undecenoic acid (10-UA) ligand dissolved in $50 \mathrm{~mL}$ anhydrous ethanol was added in a three-necked flask equipped with a thermometer, condenser tube, and dropping funnel (note that the molar ratio of the ligand $10-\mathrm{UA}$ to $\mathrm{Tb}^{3+}$ ion was $3: 1$ ). Subsequently, the prepared ethanol solution of terbium(III) nitrate was dripped slowly into a three-necked flask, and the $\mathrm{pH}$ of the solution was adjusted to 6-7 with a $1 \mathrm{~mol} / \mathrm{L} \mathrm{NaOH}$ solution until a large amount of precipitation was separated. Next, the coordination reaction was continued for $2 \mathrm{~h}$ at $70^{\circ} \mathrm{C}$ with magnetic stirring. After heating, the solution was allowed to stand overnight to precipitate completely. The product was filtered and washed with anhydrous ethanol and deionized water several times. The product was kept in a vacuum oven at $60^{\circ} \mathrm{C}$ for $24 \mathrm{~h}$ to obtain the white powder $(1.058 \mathrm{~g})$ that was the 10-UA-Tb(III) complex, and the yield was $72.8 \%$. The elemental calculation resulted in $54.53 \% \mathrm{C}$, $8.20 \% \mathrm{H}(\mathrm{C} / \mathrm{H} 6.65)$, and $15.40 \% \mathrm{O}$. The actual results were $53.60 \% \mathrm{C}, 8.02 \% \mathrm{H}(\mathrm{C} / \mathrm{H} 6.68)$, and $15.09 \% \mathrm{O}$. By changing the molar ratio of the ligand to the $\mathrm{Tb}^{3+}$ ion, other 10-UA$\mathrm{Tb}$ (III) complexes were prepared based on the above process. 


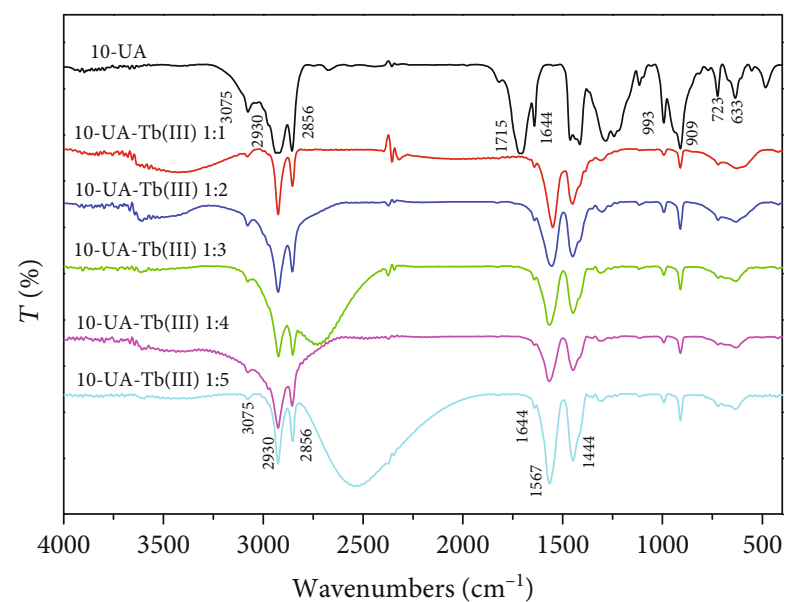

FIgURE 2: FTIR spectra of 10-UA and 10-UA-Tb(III) complexes.

2.3. Preparation of UV-Cured Film with 10-UA-Tb(III) Complex. $80 \%$ of B-369 aliphatic urethane acrylate, $15 \%$ of TMPTA reactive diluent, and $5 \%$ of photoinitiator 1173 were successively added to the plastic beaker, after which it was mixed well and stirred in an ultrasonic cleaner for 5 minutes. Subsequently, a certain amount of 10-UA-Tb(III) complexes was doped into the formulation coating and uniformly dispersed for 20 minutes. The mixed coating stood for 10 minutes and was evenly coated on a glass substrate with a thickness of $20 \mu \mathrm{m}$. The films were cured under a high-pressure mercury lamp $(1000 \mathrm{~W})$ with a UV radiation intensity of $36 \mathrm{~mJ} / \mathrm{cm}^{2}$ and a main wavelength of $365 \mathrm{~nm}$. Finally, rare earth UVcured composites were produced.

\subsection{Measurement and Characterization}

2.4.1. FTIR Spectra. The Fourier-transform infrared (FTIR) spectra of the samples were collected using a USA Nicolet Magna 380 infrared spectrometer through $\mathrm{KBr}$ tablets for wavenumbers of $400-4000 \mathrm{~cm}^{-1}$.

2.4.2. XRD Spectra. X-ray diffraction with $\mathrm{Cu}-\mathrm{K} \alpha$ radiation was carried out to characterize the crystal phase of the sample at $40 \mathrm{kV}$ and $40 \mathrm{~mA}$. The $2 \theta$ angle was collected from $3^{\circ}$ to $80^{\circ}$.

\subsubsection{Field Emission Scanning Electron Microscope (FESEM).} FESEM images of the 10-UA-Tb(III) complex and UV-cured film doped with the 10-UA-Tb(III) complex were collected using a Nova SEM450 field emission scanning electron microscope. The specimens were prepared by smearing the test samples on a conductive adhesive and then depositing gold on the surface.

2.4.4. Fluorescence Spectra. The luminescence excitation and emission spectra of 10-UA- Tb(III) complexes were performed with an F-7000 fluorescence spectrometer. The sample powder was added into a sample pool. The width of the excitation and emission slits was both $2.5 \mathrm{~nm}$, and the voltage was $400 \mathrm{v}$. The scanning speed was $1200 \mathrm{~nm} / \mathrm{min}$. For the rare earth UV-cured films, the width of excitation and emission was adjusted to $5.0 \mathrm{~nm}$.
2.4.5. Thermogravimetric Analysis. The thermal stability of the samples was collected with a TG-209 thermogravimetric analyzer. The temperature range was $50 \sim 1000^{\circ} \mathrm{C}$, and the heating rate was $10^{\circ} \mathrm{C} / \mathrm{min}$. The atmosphere was nitrogen with a gas flow rate of $100 \mathrm{~mL} / \mathrm{min}$. The data were recorded every $0.5 \mathrm{~s}$.

2.4.6. Mechanical Property Tests. The mechanical properties of the rare earth UV-cured films were investigated using pencil hardness, adhesion, and flexibility tests. The pencil hardness test was conducted according to the ASTM D3363-05 standard. The adhesion was conducted according to ASTM D3002 (0B-5B). The flexibility of the coatings was measured by the T-Bend test according to ASTM D414510. The cured coating films were tested water resistance, solvent resistance, acid resistance $(0.1 \mathrm{~mol} / \mathrm{L} \mathrm{HCl})$, and alkali resistance $(0.1 \mathrm{~mol} / \mathrm{L} \mathrm{NaOH})$.

\section{Results and Discussion}

3.1. Infrared Spectra. The FTIR spectra of the $10-\mathrm{UA}-\mathrm{Tb}(\mathrm{III})$ complexes with different ratios $\left(\mathrm{Tb}^{3+}: 10-\mathrm{UA}\right)$ and the organic ligand 10-UA are shown in Figure 2. According to Figure 2, the spectral bands of these complexes were roughly consistent. The band owing to $v(\mathrm{c}=\mathrm{o})$ of the carboxylic group in 10-UA at $1715 \mathrm{~cm}^{-1}$ disappeared and split into two new peaks at $1567 \mathrm{~cm}^{-1}$ and $1444 \mathrm{~cm}^{-1}$, which corresponded to asymmetric vibration absorption and symmetric vibration absorption of the carboxylate ion $\left(\mathrm{COO}^{-}\right)$, respectively. This result indicated that rare earth $\mathrm{Tb}(\mathrm{III})$ ions successfully coordinated with carboxyl acid ligands. Moreover, the $\Delta v\left(v_{\mathrm{as}}-v_{\mathrm{s}}\right)$ values of all complexes were approximately $123 \mathrm{~cm}^{-1}$, which is less than $200 \mathrm{~cm}^{-1}$, indicating that the $\mathrm{Tb}$ (III) ion and ligands were in the form of chelate bidentate coordination $[30,32]$. There were two absorption peaks from the ethylenic bond at $3075 \mathrm{~cm}^{-1}$ and $1644 \mathrm{~cm}^{-1}$, which were assigned to $v_{=\mathrm{CH}}$ and $v_{\mathrm{C}=\mathrm{C}}$, respectively. The bands at $2930 \mathrm{~cm}^{-1}$ and $2856 \mathrm{~cm}^{-1}$ were attributed to the asymmetric vibration absorption and symmetric vibration absorption of methylene, respectively. In addition, the in-plane rocking vibration of $-\mathrm{CH}_{2}$ was at approximately $723 \mathrm{~cm}^{-1}$. In comparison, there was a broad absorption band at approximately $3434 \mathrm{~cm}^{-1}$ due to asymmetric vibration absorption of $-\mathrm{OH}$ in the 10-UA- $\mathrm{Tb}(\mathrm{III})$ complexes.

3.2. XRD Spectra. As shown in Figure 3, the phase structure of the 10-UA-Tb(III) complex with a ratio of $1: 3\left(\mathrm{~Tb}^{3+}:-\right.$ ligand) was revealed by XRD. There were two sharp X-ray diffraction peaks at $2 \theta=3.81^{\circ}$ and $2 \theta=29.46^{\circ}$. The strong and sharp peak at $2 \theta=29.46^{\circ}$ belongs to the (111) reflection of Tb-10-UA. In addition, there was a weak diffuse reflection at $2 \theta=6.75^{\circ}$. These data confirmed the existence of a crystal structure, and a characteristic peak of $\mathrm{Tb}_{4} \mathrm{O}_{7}$ appeared at $29.46^{\circ}$, which proved that the terbium ion successfully coordinated with the 10-Undecenoic acid ligand.

3.3. Morphology Analysis. With a cotton swab, the powder sample was smeared on a conductive adhesive. The surface of the sample was sprayed with gold and then tested. The SEM images of the 10-UA- $\mathrm{Tb}(\mathrm{III})$ complex are presented in 


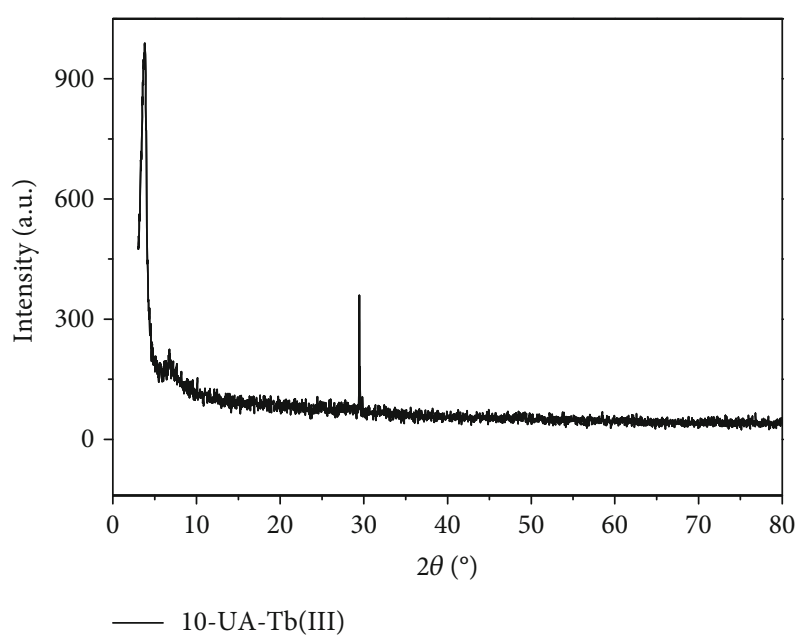

FIGURE 3: XRD curve of the 10-UA-Tb(III) complex.

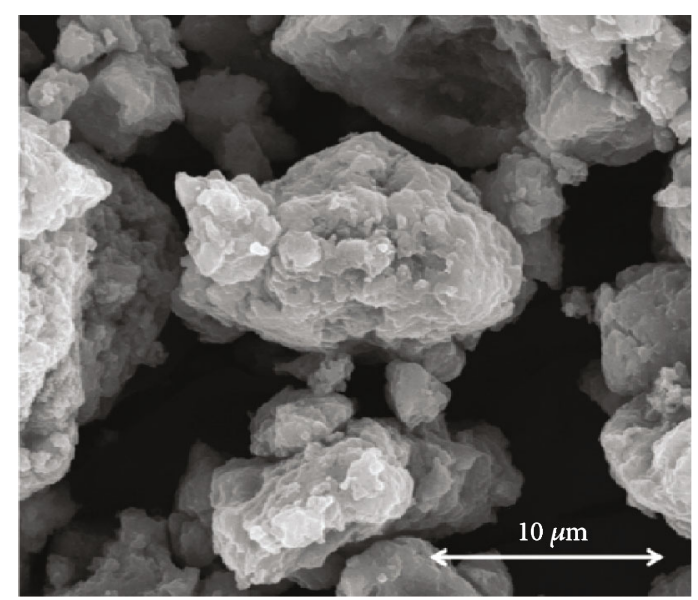

FIgURE 4: SEM image of the 10-UA-Tb(III) complex.

Figure 4. The result showed that the 10-UA-Tb(III) complex had a rough rock structure with a size belonging in the microscopic regime. Its edge line was clear. There was an agglomeration phenomenon that resulted in the appearance of large particles.

The morphology of the rare earth UV-cured film containing $2.0 \%$ of the $10-\mathrm{UA}-\mathrm{Tb}$ (III) complex was studied by SEM. Figure 5(a) shows the surface morphology of the rare earth polymer film, and Figure 5(b) shows the crosssection morphology of the rare earth polymer film. It is shown that the Tb-UA complex cannot be dissolved in the polymer matrix. The rare earth UV-cured composite exhibited a heterogeneous morphology. There were discrete particles of the 10-UA-Tb(III) complex mixed uniformly in the polymer matrix, and they were evenly dispersed, although they appeared aggregated.

3.4. Luminescence Testing. The excitation spectra and the emission spectra of 10-UA- $\mathrm{Tb}$ (III) complexes with different ligand contents are shown in Figures 6(a) and 6(b), respectively. As shown in Figure 6(a), the 10-UA-Tb(III) complexes had a wide absorption range from $270 \mathrm{~nm}$ to $400 \mathrm{~nm}$. Among them, the maximum excitation wavelength of all complexes was $273 \mathrm{~nm}$. Selecting $273 \mathrm{~nm}$ as the excitation wavelength to excite samples, the emission spectra are measured in Figure 6(b). From the emission spectra, the emission peaks from the 10-UA- $\mathrm{Tb}(\mathrm{III})$ complexes with different ligand contents were similar. The emission peaks from the rare earth complexes were at $491,548,586$, and $623 \mathrm{~nm}$, which belonged to the characteristic peaks of the $\mathrm{Tb}^{3+}$ ions. The first was attributed to the transition of ${ }^{5} \mathrm{D}_{4} \longrightarrow{ }^{7} \mathrm{~F}_{6}$, the second to the transition of ${ }^{5} \mathrm{D}_{4} \longrightarrow{ }^{7} \mathrm{~F}_{5}$, the third to the transition of ${ }^{5} \mathrm{D}_{4} \longrightarrow{ }^{7} \mathrm{~F}_{4}$, and the fourth to the transition of ${ }^{5} \mathrm{D}_{4} \longrightarrow{ }^{7} \mathrm{~F}_{3}$. Among these transitions, the highest fluorescence intensity emission peak was the ${ }^{5} \mathrm{D}_{4} \longrightarrow{ }^{7} \mathrm{~F}_{5}$ transition at $548 \mathrm{~nm}$, which resulted in a green emission. The emission bands were narrow, and the peak shapes were sharp, which indicated that the 10-UA-Tb(III) complexes possessed good monochromatic properties. Furthermore, the proportion of ligands had a significant impact on fluorescence intensity. From Figure 6(b), the fluorescence intensity of the 10-UA-Tb(III) complex with a ratio of $1: 4\left(\mathrm{~Tb}^{3+}: 10-\mathrm{UA}\right)$ was the strongest. It is possible that when the organic ligand content increases, more ultraviolet light is absorbed to transfer energy to the $\mathrm{Tb}^{3+}$ ion, and the $\mathrm{Tb}^{3+}$ ion radiated more energy through the f-f energy level transition. Moreover, the triplet energy level of the 10-UA was better matched with the $f$ energy level of the terbium(III) ion, which could be sensitized effectively. However, the fluorescence intensity decreased when the ratio was $1: 5$. This phenomenon was caused by the concentration quenching effect. That is, the proportion of ligands had a significant impact on fluorescence intensity. At first, the increase of fluorescence intensity follows with the increase of the ligand number. The fluorescence intensity will decrease when the ligand number reached a number.

Different amounts of 10-UA-Tb(III) complexes were doped into the as-prepared UV-cured coatings to obtain rare earth polymer composite coatings; the thin doped films were coated on glass slides and cured under a $1000 \mathrm{~W}$ UV-curing machine. The luminescence of the composites containing $0.0,0.5,1.0,1.5,2.0,2.5$, and 3.0 wt $\%$ of $10-\mathrm{UA}-\mathrm{Tb}(\mathrm{III}) \mathrm{com}-$ plexes was investigated, as shown in Figure 7. According to Figure $7(\mathrm{a})$, there were two obvious excitation peaks at $272 \mathrm{~nm}$ and $306 \mathrm{~nm}$ in all of the UV-cured composites. Selecting $272 \mathrm{~nm}$ as the maximum excitation wavelength to excite the sample, the emission spectra of the rare earth polymer composites are shown in Figure 7(b). The films doped with different amounts of the rare earth complex all radiated the characteristic emission peaks of terbium ions, which are located at $492 \mathrm{~nm}, 547 \mathrm{~nm}$, and $588 \mathrm{~nm}$. Moreover, the concentration was too low to emit strong fluorescence. When the content of the 10-UA-Tb(III) complex in the UV-cured film increased gradually, the fluorescence intensity was enhanced correspondingly.

3.5. Thermal Stability. Figure 8 shows the thermal stability of the 10-UA- $\mathrm{Tb}$ (III) complex. The decomposition process of the $10-\mathrm{UA}-\mathrm{Tb}$ (III) complex from $50^{\circ} \mathrm{C}$ to $1000^{\circ} \mathrm{C}$ was roughly divided into the following stages: $50 \sim 200^{\circ} \mathrm{C}$, $200 \sim 499.7^{\circ} \mathrm{C}$, and $499.7 \sim 1000^{\circ} \mathrm{C}$. There was a low weight loss of approximately $2.20 \%$ within $50 \sim 200^{\circ} \mathrm{C}$ due to the trace 


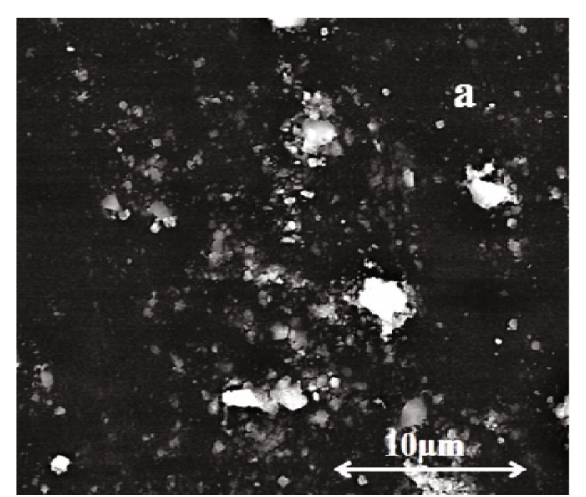

(a)

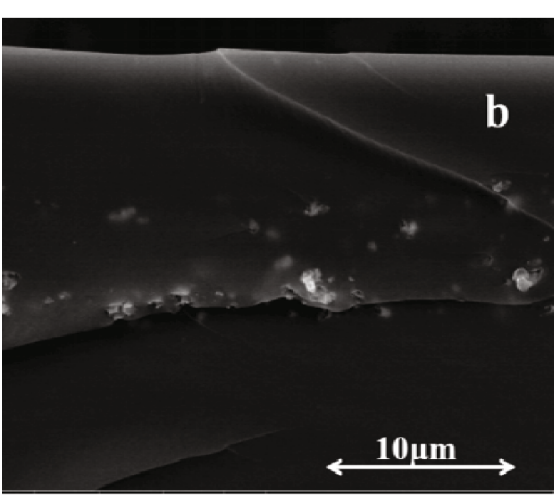

(b)

FIGURE 5: SEM images of rare earth UV-cured composite: (a) surface morphology and (b) section morphology.

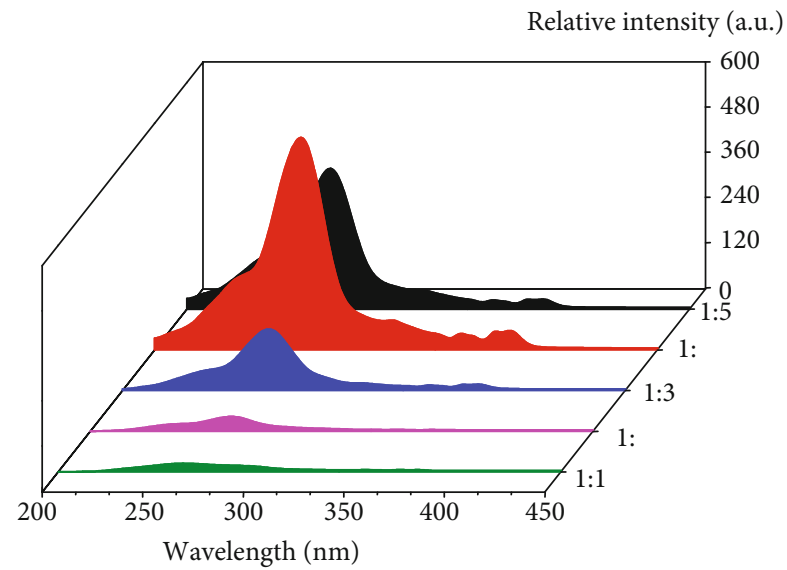

(a)

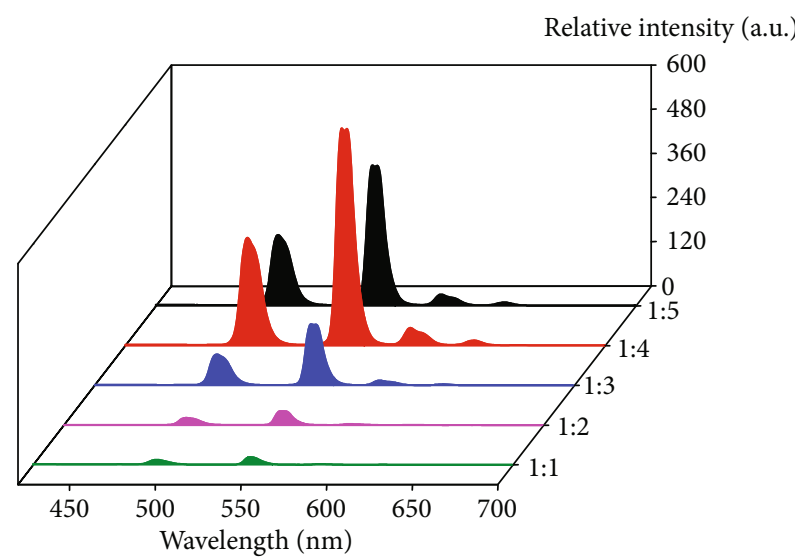

(b)

FIgURE 6: Excitation spectra (a) and emission spectra (b) of the 10-UA-Tb(III) complex.

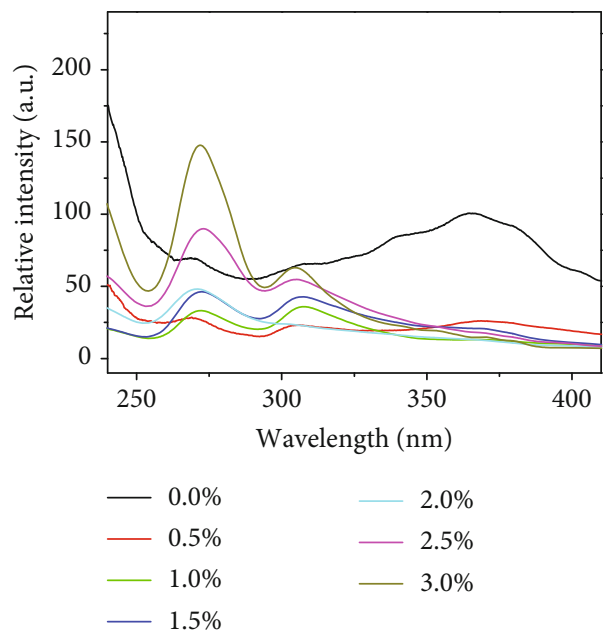

(a)

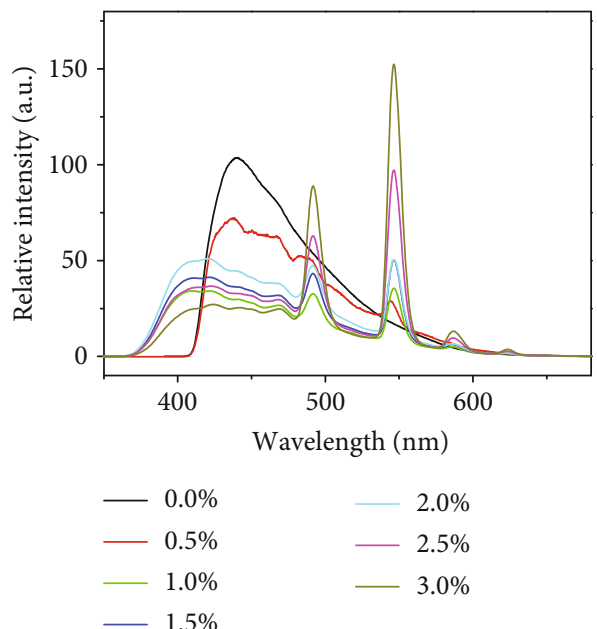

(b)

FIGURE 7: Luminescence properties of rare earth UV-cured composite: (a) excitation spectra and (b) emission spectra.

amount of water removed. Subsequently, there was an evident decline from $200.0^{\circ} \mathrm{C}$ to $499.7^{\circ} \mathrm{C}$ with a total of $67.48 \%$ weight loss, which could be attributed to cracking of the 10Undecenoic acid skeleton. There were two maximum decom- position rates for this process at $347.8^{\circ} \mathrm{C}$ and $465.1^{\circ} \mathrm{C}$. Then, there was a gentle incline from $499.7^{\circ} \mathrm{C}$ to $699.2^{\circ} \mathrm{C}$, which decomposed by $6.71 \%$ and remained at approximately $23.61 \%$. This process could be the decomposition of the 


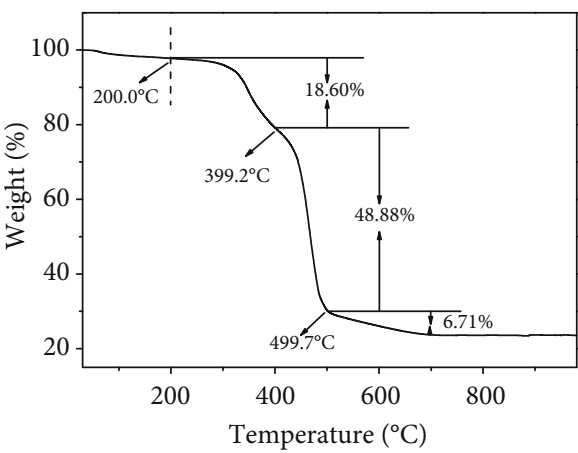

(a)

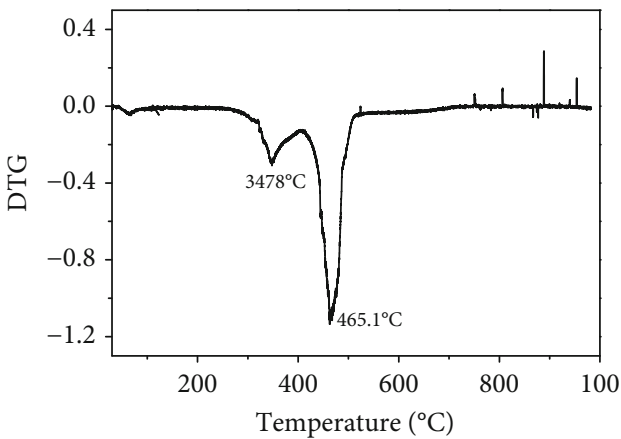

(b)

Figure 8: (a) TG and (b) DTG curves of the 10-UA-Tb(III) complex.

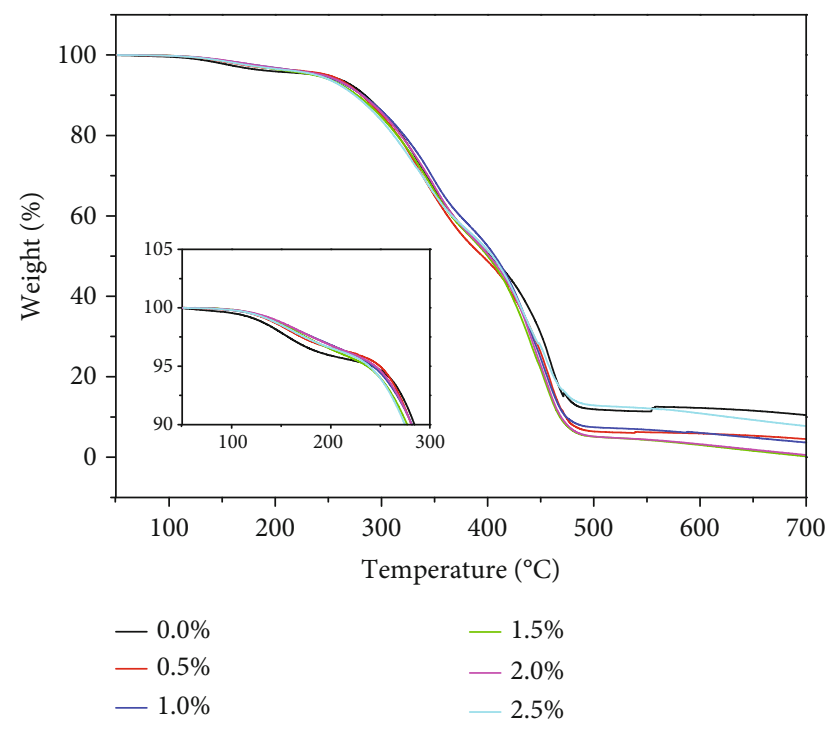

Figure 9: (a) TG and (b) DTG curves of the 10-UA-Tb(III) complex.

terbium hydroxide, where $\mathrm{Tb}(\mathrm{OH})_{3}$ decomposed into $\mathrm{TbO}(\mathrm{OH})$ and then $\mathrm{TbO}(\mathrm{OH})$ was transferred to $\mathrm{Tb}_{2} \mathrm{O}_{3}$. The test result was in agreement with the speculative structure of the 10-UA- $\mathrm{Tb}$ (III) complex above. This proved that the 10-UA-Tb(III) complex had good thermal stability.

The stability of the UV-cured coating films doped with different contents of rare earth complexes was explored, as shown in Figure 9. According to the TG curves, the addition of the 10-UA-Tb(III) complex did not have a strong influence on the UV-cured coatings because their thermal stability was approximately the same from $50^{\circ} \mathrm{C}$ to $700^{\circ} \mathrm{C}$. It began to slowly decompose from $100^{\circ} \mathrm{C}$ to $240^{\circ} \mathrm{C}$. In this interval, the stability of the rare earth UV-cured composite was slightly better than that of the UV-cured coating undoped with a rare earth complex. Subsequently, it decomposed rapidly at $240^{\circ} \mathrm{C}$, and the decomposition was completed at $500^{\circ} \mathrm{C}$. As a whole, the addition of the 10-UA- $\mathrm{Tb}$ (III) complex did not have a distinct impact on the original UV-cured coating. The reason may be that the thermal properties of UV-cured film are mainly influenced from the polymer matrix. The addition of the
TABLE 1: The curing time and properties of UV-cured films.

\begin{tabular}{lccccc}
\hline Content (wt \%) & 0 & 1.0 & 3.0 & 5.0 & 10.0 \\
\hline Curing time (s) & 28 & 28 & 24 & 25 & 21 \\
Pencil hardness & $6 \mathrm{H}$ & $6 \mathrm{H}$ & $6 \mathrm{H}$ & $6 \mathrm{H}$ & $6 \mathrm{H}$ \\
Adhesion/grade & $5 \mathrm{~B}$ & $4 \mathrm{~B}$ & $3 \mathrm{~B}$ & $3 \mathrm{~B}$ & $3 \mathrm{~B}$ \\
Flexibility & $3 \mathrm{~T}$ & $3 \mathrm{~T}$ & $3 \mathrm{~T}$ & $3 \mathrm{~T}$ & $3 \mathrm{~T}$ \\
Solvent resistance/MEK & $>250$ & $>250$ & $>250$ & $>250$ & $>250$ \\
\hline
\end{tabular}

10-UA-Tb(III) complex did have a slightly influence on decomposed rate of the UV-cured films from $100^{\circ} \mathrm{C}$ to $240^{\circ} \mathrm{C}$. The low amount of Tb-UA complex has a slight influence on the thermal properties of the UV-cured film.

3.6. Mechanical Properties of the UV-Cured Film. The photopolymerization efficiency and mechanical properties of the rare earth UV-cured composites were evaluated, including curing time, pencil hardness, adhesion, and flexibility, as shown in Table 1. The curing time of the rare earth UVcured films was slightly shortened with an increase with the $10-\mathrm{UA}-\mathrm{Tb}(\mathrm{III})$ complex. A possible explanation is that the addition of rare earth complexes enhanced the ability to absorb ultraviolet light from the entire UV-cured system, which led to the promotion of the cleavage of the photoinitiator 1173. Thus, it effectively promoted cross-linking curing of the resin and monomer. The pencil hardness of all films was high at $6 \mathrm{H}$. The addition of rare earth complexes had a little effect on the pencil hardness. The adhesion of the composite films decreased perhaps because the cross-linking density was reduced after curing with the addition of the rare earth complexes. However, the flexibility of the films was good. From Table 1, we can notice that the UV-cured films showed good solvent resistance for methyl ethyl ketone. It revealed that the UV-cured films had the structure of tight crosslink network. That the rare earth complexes had no effect on solvent resistance may be the 10-UA containing double bond copolymerized with the resin or reactive diluent. Moreover, the rare earth UV-cured films were soaked in $0.1 \mathrm{~mol} / \mathrm{L}$ $\mathrm{HCl}, 0.1 \mathrm{~mol} / \mathrm{L} \mathrm{NaOH}$, and water. After $48 \mathrm{~h}$, the composite films were detached and wrinkled in hydrochloric acid 
solution and sodium hydroxide solution, but there was no change in water.

\section{Conclusions}

A novel terbium complex was synthesized and coordinated with 10 -Undecenoic acid via a solution precipitation method. The coordinated structure and molecular component of the 10-UA-Tb(III) complex were studied by a series of characterization methods that indicated that the 10-UA- Tb(III) complex was a chelate bidentate complex, and its molecular formula was $\mathrm{Tb}\left(\mathrm{C}_{11} \mathrm{H}_{19} \mathrm{O}_{2}\right)_{3} \cdot \mathrm{H}_{2} \mathrm{O}$. The 10 -UA- $\mathrm{Tb}$ (III) complex showed excellent luminescence properties. In particular, the complex with a ratio of $1: 4\left(\mathrm{~Tb}^{3+}: 10\right.$-UA) emitted the highest fluorescence intensity. Next, the 10-UA-Tb(III) complex was doped into a UV-cured coating to prepare rare earth UV-cured composites. As a result, the composite exhibited a heterogeneous morphology, as seen in SEM images, and the composite also possessed a luminescence peculiarity that emitted a green light. For mechanical properties, the curing time slightly shortened. The hardness, adhesion, and flexibility were good. The addition of the 10-UA-Tb(III) complex did not conspicuously change the thermal stability of the UV-cured coating. In summary, this research can provide a direction to further explore rare earth organic hybrid composites that could be applied to UV-cured coatings and luminescence materials. The complex of Te-Undecenoic acid is suitable for UV-curing material. The composites of them can be cured less than $60 \mathrm{~s}$ and have good photoluminescent, mechanical properties after UV irradiation.

\section{Data Availability}

The data used to support the findings of this study are available from the corresponding author upon request.

\section{Conflicts of Interest}

There are no conflicts to declare.

\section{Acknowledgments}

The authors appreciate the financial support provided by the National Natural Scientific Foundation of China (21364008), the Natural Science and Technology Foundation from the Jiangxi Education Department (DA201702347), and the Graduate Innovation Funds of Nanchang Hangkong University (YC2017011).

\section{References}

[1] D. I. Alexandropoulos, L. Cunha-Silva, L. Pham, V. Bekiari, G. Christou, and T. C. Stamatatos, "Tetranuclear lanthanide(III) complexes with a zigzag topology from the use of pyridine-2,6-dimethanol: synthetic, structural, spectroscopic, magnetic and photoluminescence studies," Inorganic Chemistry, vol. 53, no. 6, pp. 3220-3229, 2014.

[2] J. G. Bünzli, "Review: Lanthanide coordination chemistry: from old concepts to coordination polymers," Journal of Coordination Chemistry, vol. 67, no. 23-24, pp. 3706-3733, 2014.
[3] S. Bangarigadu-Sanasy, C. R. Sankar, P. A. Dube, J. E. Greedan, and H. Kleinke, "Magnetic properties of Tl9LnTe6, Ln = Ce, $\mathrm{Pr}, \mathrm{Tb}$ and Sm," Journal of Alloys and Compounds, vol. 589, pp. 389-392, 2014.

[4] B. L. An, X. D. Huang, J. M. Zhang, X. Y. Zhu, and J. Q. Xu, "Synthesis and strong luminescence of water soluble lanthanide complexes sensitized by a new tridentate organic ligand," Journal of Luminescence, vol. 187, pp. 340-346, 2017.

[5] H. L. Tan, J. Wu, and Y. Chen, “Terbium(III) based coordination polymer microparticles as a luminescent probe for ascorbic acid," Microchimica Acta, vol. 181, no. 11-12, pp. 1431-1437, 2014.

[6] R. Z. Cui, W. Q. Liu, L. Zhou et al., "Highly efficient green phosphorescent organic electroluminescent devices with a terbium complex as the sensitizer," Dyes and Pigments, vol. 136, pp. 361-367, 2017.

[7] J. Feng and H. J. Zhang, "Hybrid materials based on lanthanide organic complexes: a review," Chemical Society Reviews, vol. 42, no. 1, pp. 387-410, 2013.

[8] M. Hatanaka and A. Osawa, "Computational study on the luminescence quantum yields of terbium complexes with 2,2'-bipyridine derivative ligands," Physical Chemistry Chemical Physics, vol. 20, no. 5, pp. 3328-3333, 2018.

[9] K. P. Zhuravlev, V. A. Kudryashova, and V. I. Tsaryuk, "Luminescence and energy transfer processes in europium and terbium complexes with 2-substituted cycloalkanones and 1,10-phenanthroline derivatives," Journal of Photochemistry and Photobiology A: Chemistry, vol. 314, pp. 14-21, 2016.

[10] K. Burek, S. Eidner, S. Kuke, and M. U. Kumke, "Intramolecular deactivation processes of electronically excited lanthanide(III) complexes with organic acids of low molecular weight," Spectrochimica Acta A, vol. 191, pp. 36-49, 2018.

[11] Y. F. Geng, P. Li, J. Z. Li, X. M. Zhang, Q. D. Zeng, and C. Wang, "STM probing the supramolecular coordination chemistry on solid surface: structure, dynamic, and reactivity," Coordination Chemistry Reviews, vol. 337, pp. 145-177, 2017.

[12] B. Kumar, G. Kaur, and S. B. Rai, "Acetylsalicylic acid sensitized lasing luminescence of terbium complex in PVA: a case of energy avalanche via 1, 10-phenanthroline," Journal of Photochemistry and Photobiology A: Chemistry, vol. 332, pp. 413-421, 2017.

[13] M. J. Ma, C. C. Li, D. K. Shu, C. Wang, and P. Xi, "Synthesis and characterization of bright green terbium coordination complex derived from 1,4-bis(carbonylmethyl)terephthalate: structure and luminescence properties," Spectrochimica Acta Part A: Molecular and Biomolecular Spectroscopy, vol. 190, pp. 68-75, 2017.

[14] F. Bauer, U. Decker, S. Naumov, and C. Riedel, "Photoinitiator-free UV curing and matting of acrylate-based nanocomposite coatings: Part 3," Progress in Organic Coatings, vol. 77, no. 6, pp. 1085-1094, 2014.

[15] L. Fertier, H. Koleilat, M. Stemmelen et al., "The use of renewable feedstock in UV-curable materials - A new age for polymers and green chemistry," Progress in Polymer Science, vol. 38, no. 6, pp. 932-962, 2013.

[16] T. Ç. Çanak and I. E. Serhatl, "Synthesis of fluorinated urethane acrylate based UV-curable coatings," Progress in Organic Coating, vol. 76, no. 2-3, pp. 388-399, 2013.

[17] S. W. Lee, J. W. Park, C. H. Park et al., "UV-curing and thermal stability of dual curable urethane epoxy adhesives for temporary bonding in 3D multi-chip package process," 
International Journal of Adhesion and Adhesives, vol. 44, pp. 138-143, 2013.

[18] D. K. Patel, A. H. Sakhaei, M. Layani, B. Zhang, Q. Ge, and S. Magdassi, "Highly stretchable and UV curable elastomers for digital light processing based 3D printing," Advanced Materials, vol. 29, no. 15, p. 1606000, 2017.

[19] M. Periolatto and F. Ferrero, "Cotton and polyester surface modification by methacrylic silane and fluorinated alkoxysilane via sol-gel and UV-curing coupled process," Surface and Coatings Technology, vol. 271, pp. 165-173, 2015.

[20] M. Mohseni, S. Bastani, and A. Jannesari, "Influence of silane structure on curing behavior and surface properties of solgel based UV-curable organic-inorganic hybrid coatings," Progress in Organic Coatings, vol. 77, no. 7, pp. 1191-1199, 2014.

[21] H. Xie and W. F. Shi, "Polymer/SiO2 hybrid nanocomposites prepared through the photoinitiator-free UV curing and solgel processes," Composites Science and Technology, vol. 93, pp. 90-96, 2014.

[22] S. W. Lee, J. W. Park, C. H. Park et al., "Optical properties and UV-curing behaviors of optically clear PSA- $\mathrm{TiO}_{2}$ nano-composites," International Journal of Adhesion and Adhesives, vol. 44, pp. 200-208, 2013.

[23] B. Faure, G. Salazar-Alvarez, A. Ahniyaz et al., "Dispersion and surface functionalization of oxide nanoparticles for transparent photocatalytic and UV-protecting coatings and sunscreens," Science and Technology of Advanced Materials, vol. 14, no. 2, pp. 023001-023304, 2013.

[24] Y. Wang, F. Liu, and X. X. Xue, "Morphology and properties of UV-curing epoxy acrylate coatings modified with methacrylPOSS," Progress in Organic Coating, vol. 78, pp. 404-410, 2015.

[25] B. Yu, Y. J. Tao, L. Liu et al., "Thermal and flame retardant properties of transparent UV-curing epoxy acrylate coatings with POSS-based phosphonate acrylate," RSC Advances, vol. 5, no. 92, pp. 75254-75262, 2015.

[26] D. V. Lapaev, V. G. Nikiforov, G. M. Safiullin et al., "UV laserinduced enhancement of photoluminescence intensity in vitrified terbium(III) $\beta$-diketonate complex film in air," Journal of Luminescence, vol. 194, pp. 407-413, 2018.

[27] F. A. Rafiqi and K. Majid, "Synthesis, characterization, luminescence properties and thermal studies of polyaniline and polythiophene composites with rare earth terbium(III) complex," Synthetic Metals, vol. 202, pp. 147-156, 2015.

[28] B. J. Gao, W. Zhang, Z. G. Zhang, and Q. Lei, "Preparation of polymer-rare earth complex using salicylic acid-containing polystyrene and its fluorescence emission property," Journal of Luminescence, vol. 132, no. 8, pp. 2005-2011, 2012.

[29] M. Zhao, R. Tang, and S. Xua, "Investigations into the bovine serum albumin binding and fluorescence properties of $\mathrm{Tb}$ (III) complex of a novel 8-hydroxyquinoline ligand," Spectrochimica Acta Part A: Molecular and Biomolecular Spectroscopy, Q. Shen, Z. F. Yang, and R. R. Tang, Eds., vol. 135, pp. 953958, 2015.

[30] Y. W. Wu, H. X. Hao, Q. Y. Wu, Z. Gao, and H. Xie, "Preparation and luminescent properties of the novel polymer-rare earth complexes composed of poly(ethylene-co-acrylic acid) and europium ions," Optical Materials, vol. 80, pp. 65-70, 2018.
[31] H. N. Wanga, L. Fanga, Z. Zhang et al., "Light-induced rare earth organic complex/shape-memory polymer composites with high strength and luminescence based on hydrogen bonding," Composites Part A Applied Science and Manufacturing, vol. 125, p. 105525, 2019.

[32] B. J. Gao, L. Fang, and J. Y. Men, "Studies on preparation, structure and fluorescence emission of polymer-rare earth complexes composed of aryl carboxylic acid-functionalized polystyrene and $\mathrm{Tb}(\mathrm{III})$ ion," Polymer, vol. 53, no. 21, pp. 4709-4717, 2012. 